\title{
Variants in $K C N Q 1$ are associated with susceptibility to type 2 diabetes in the population of mainland China
}

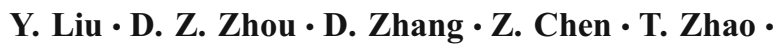 \\ Z. Zhang $\cdot$ M Ning $\cdot$ X. Hu $\cdot$ Y. F. Yang $\cdot$ Z. F. Zhang $\cdot$ \\ L. Yu $\cdot$ L. He $\cdot$ H. Xu
}

Received: 10 December 2008 / Accepted: 3 April 2009/Published online: 12 May 2009

(C) The Author(s) 2009. This article is published with open access at Springerlink.com

\author{
Abstract \\ Aims/hypothesis Two recent genome-wide association studies \\ have identified several novel type 2 diabetes susceptibility \\ variants in intron 15 of the $K C N Q 1$ gene. We aimed to evaluate \\ the effects of the variants in KCNQ1 on type 2 diabetes and \\ metabolic traits in the population of mainland China. \\ Methods Three candidate single nucleotide polymorphisms \\ were genotyped in 1,912 individuals with type 2 diabetes \\ Y. Liu and D. Z. Zhou contributed equally to this study. \\ Electronic supplementary material The online version of this article \\ (doi:10.1007/s00125-009-1375-y) contains supplementary material, \\ which is available to authorised users. \\ Y. Liu $\cdot$ D. Z. Zhou $\cdot$ D. Zhang $\cdot$ Z. Chen $\cdot$ T. Zhao $\cdot$ Z. Zhang $\cdot$ \\ M. Ning $\cdot$ Y. F. Yang $\cdot$ L. He $(\bowtie) \cdot H$. Xu $(\bowtie)$ \\ Key Laboratory of Nutrition and Metabolism, Institute for \\ Nutritional Sciences, Shanghai Institutes for Biological Sciences, \\ Graduate School of the Chinese Academy of Sciences, \\ Chinese Academy of Sciences, \\ 294 Taiyuan Road, \\ Shanghai 200031, People's Republic of China \\ e-mail: helin@bio-x.cn \\ e-mail: hexuc@yahoo.com.cn \\ Y. Liu $\cdot$ D. Z. Zhou $\cdot$ D. Zhang $\cdot$ Z. Chen $\cdot$ T. Zhao $\cdot$ Z. Zhang $\cdot$ \\ M. Ning $\cdot$ Y. F. Yang $\cdot$ L. Yu $\cdot$ L. He $\cdot$ H. Xu \\ Bio-X Center, Shanghai Jiao Tong University, \\ Shanghai, People's Republic of China \\ X. Hu \\ Ruijin Hospital, Luwan Branch, \\ Shanghai, People's Republic of China

\section{Z. F. Zhang} \\ Department of Epidemiology, UCLA School of Public Health, \\ Los Angeles, CA, USA \\ L. He \\ Institutes of Biomedical Sciences, Fudan University, \\ Shanghai, People's Republic of China
}

and 2,041 normal controls using the ligase detection reaction method.

Results We confirmed the association of $K C N Q 1$ with type 2 diabetes in the population of mainland China. Allele frequency ORs of the three single nucleotide polymorphisms (SNPs) were: rs2237892 (OR 1.19, 95\% CI 1.08-1.31, $\left.p=3.0 \times 10^{-4}\right) ; \quad$ rs2237895 (OR $1.20,95 \%$ CI $1.09-$ $1.32, p=1.9 \times 10^{-4}$ ); and rs2237897 (OR 1.24, 95\% CI 1.13$\left.1.36, p=3.9 \times 10^{-5}\right)$. We also found a significant difference in the distribution of the global haplotypes between the type 2 diabetes group and the normal control group $\left(p=2.6 \times 10^{-5}\right)$. In addition, in the control group SNP rs2237892 was marginally associated with increasing fasting plasma glucose and SNPs rs2237892 and rs2237897 were associated with $\mathrm{HbA}_{1 \mathrm{c}}$. Furthermore, for all three variants, homozygous carriers of the diabetes-associated allele had significantly decreased BMI and waist circumferences.

Conclusions/interpretation Our investigation confirmed the effects of $K C N Q 1$ variants on type 2 diabetes risk in the Chinese population.

Keywords Association $\cdot K C N Q 1 \cdot$ Mainland Chinese population - Type 2 diabetes

\section{Abbreviations \\ LD Linkage disequilibrium \\ PAR Population attributable risk \\ SNP Single nucleotide polymorphism}

\section{Introduction}

Type 2 diabetes is a major health problem affecting more than 200 million individuals worldwide. Its prevalence is 
increasing in many countries, especially in the developing countries [1]. For example, the total number of people with diabetes in China is estimated to increase from 20.8 million in 2000 to 42.3 million by 2030 . Type 2 diabetes is characterised by the presence of insulin resistance and pancreatic beta cell dysfunction, resulting from the interaction of genetic and environmental factors.

So far a few genes, identified through linkage scans or the candidate gene approach, have been confirmed as being associated with type 2 diabetes e.g. PPARG, KCNJ11 and TCF7L2 [2-4]. Recently, the use of genome-wide association scans as an investigative tool has led to a qualitative leap in identifying diabetes-related genes. Genome-wide association studies conducted in large-scale case-control samples by several independent European and American research groups have identified several novel genes and loci with modest effects on the risk of type 2 diabetes (OR 1.14-1.20), such as SLC30A8, HHEX, CDKAL1, CDKN2A, $C D K N 2 B, I G F 2 B P 2$ and FTO [5-10]. These studies have been replicated and results confirmed in several other ethnic groups [11-17].

The two most recent genome-wide association studies, in the Japanese population, have identified the association of a novel gene (KCNQ1) with the risk of type 2 diabetes; a similar association was also detected in some Asian and European populations in these studies [18, 19]. Recently, Tan et al. also found variants in $K C N Q 1$ to be associated with type 2 diabetes, fasting glucose and beta cell function in 3,734 individuals belonging to three ethnic groups living in Singapore [20]. It is well known that there are significant differences in the frequencies of some genetic variations among different ethnic groups and geographic regions. Therefore, we decided to investigate further the contribution of $K C N Q 1$ to the aetiology of type 2 diabetes and to determine whether variants of the KCNQ1 gene were associated with the susceptibility to type 2 diabetes and diabetes-related metabolic traits in the population of mainland China. We also used haplotype analysis and the best-fitting model test in our investigation.

\section{Methods}

Participants In this study, 3,953 Chinese Han participants were recruited from Shanghai, China; these comprised 1,912 unrelated type 2 diabetic individuals (785 men, 1,127 women; age 63.9 \pm 9.5 years) and 2,041 control individuals (635 men, 1,406 women; age 58.1 \pm 9.4 years). The study population overlapped completely with that used in our previous study [16]. Diabetic participants were defined in accordance with WHO criteria. Controls with a fasting plasma glucose concentration $<6.1 \mathrm{mmol} / 1$ were enrolled from the same geographical region. A standard informed consent procedure was included in the protocol, and was reviewed and approved by the Ethics Committee of the Shanghai Institute for Biological Sciences. Participants gave their consent after the nature of study had been fully explained.

Blood samples were drawn for biochemical measurements (fasting plasma glucose, $\mathrm{HbA}_{1 \mathrm{c}}$, total cholesterol, triacylglycerol, HDL-cholesterol and LDL-cholesterol). Height, weight, waist and hip circumferences, and blood pressure were measured in all individuals. Data are showed as medians (25-75\% range) or means $\pm \mathrm{SD}$ (Table 1 ).

Single nucleotide polymorphism selection For the KCNQ1 gene, five single nucleotide polymorphisms (SNPs) (rs2237892, rs2237895, rs2237897, rs2074196 and rs2283228) were identified as having the most significant association with type 2 diabetes based on previous studies
Table 1 Clinical characteristics of the study participants

Data are medians $(25-75 \%$ range) or means $\pm \mathrm{SD}$

\begin{tabular}{lll}
\hline Characteristic & Type 2 diabetes & Controls \\
\hline Number & 1,912 & 2,041 \\
Men/women $(n / n)$ & $785 / 1,127$ & $635 / 1,406$ \\
Age (years) & $63.9 \pm 9.5$ & $58.1 \pm 9.4$ \\
BMI $\left(\mathrm{kg} / \mathrm{m}^{2}\right)$ & $25.3 \pm 3.48$ & $24.5 \pm 3.24$ \\
Waist to hip ratio & $0.89 \pm 0.06$ & $0.86 \pm 0.06$ \\
Fasting blood glucose $(\mathrm{mmol} / \mathrm{l})$ & $7.42(6.08-9.49)$ & $4.89(4.51-5.25)$ \\
Triacylglycerol (mmol/l) & $1.51(1.07-2.19)$ & $1.34(0.94-1.91)$ \\
Total cholesterol (mmol/1) & $4.40(3.82-5.03)$ & $4.44(3.9-5.02)$ \\
HDL-cholesterol (mmol/l) & $1.14(0.96-1.35)$ & $1.22(1.03-1.46)$ \\
LDL-cholesterol (mmol/1) & $2.7(2.24-3.2)$ & $2.74(2.33-3.26)$ \\
Systolic blood pressure $(\mathrm{mmHg})$ & $140(127-151)$ & $130(120-141)$ \\
Diastolic blood pressure $(\mathrm{mmHg})$ & $80(76-90)$ & $80(74-89)$ \\
HbA ${ }_{1 \mathrm{c}}(\%)$ & $7.11(6.38-8.31)$ & $5.80(5.46-6.11)$ \\
Obesity $(\%)$ & 20.7 & 14.1 \\
\hline
\end{tabular}


[18-20]. After considering the linkage disequilibrium (LD) structure based on HapMap Han Chinese and the pairwise linkage disequilibrium $D^{\prime}$ and $r^{2}$ values, we used rs2237892 to represent rs2074196 and rs2283228 $\left(r^{2}=0.73\right.$ and 0.95 , respectively) and thus selected three representative variants (rs2237892, rs2237895 and rs2237897) to be genotyped in our study.

Genotyping High molecular weight genomic DNA was prepared from venous blood using the QuickGene 610L Automatic DNA/RNA Extraction System (Fujifilm, Tokyo, Japan). All the genotyping experiments were done using ligase detection reactions [21]. All genotyping success rates were above $98 \%$ and all mismatch rates were below $1 \%$ in 1641 duplicate samples.

Statistical analysis We used SHEsis [22] to perform the Hardy-Weinberg equilibrium test, to compare the differences of allele, genotype and haplotype frequencies between cases and controls and to calculate LD coefficients $\left(D^{\prime}\right.$ and $\left.r^{2}\right)$ in the control group.

To establish the closest best-fit model for each SNP, we carried out the logistic regression analysis by comparing additive, dominant and recessive models with age, sex and $\log$ BMI as covariants, and the model that had the lowest Akaike's information criterion value was considered to be the best-fitting model for the respective SNP. In the additive model, homozygotes for the risk allele (1/1), heterozygotes $(1 / 0)$ and homozygotes for the non-risk allele $(0 / 0)$ were coded to an ordered categorical variable for the genotype (2, 1 and 0 , respectively). The dominant model was defined as $1 / 1+1 / 0$ vs $0 / 0$ and the recessive model as $1 / 1$ vs
$1 / 0+0 / 0$. The association of the SNPs with type 2 diabetes was assessed by logistic regression after adjusting for sex, age and $\log _{e}$ BMI. The population attributable risk (PAR) [23] was calculated as:

$\mathrm{PAR}=1-\frac{1}{n_{\mathrm{c}}} \sum_{i \in \text { Case }} \frac{1}{\mathrm{OR}_{i}}$

where $n_{\mathrm{c}}$ is the number if individuals in each case group and $\mathrm{OR}_{i}$ is equal to $\beta \times Y$ (the estimated $\mathrm{OR}$ of the $i$ th individual in each case group [ $\beta$ is the regression coefficient vector in terms of $Y$, and $Y$ is the term for the respective SNP in the logistic regression model]). In addition, to analyse the independent effect of each SNP in the KCNQ1 gene, we carried out a conditional analysis by including the most significant SNP in the region and the SNP being tested, coded according to the most appropriate genetic model, combined with age, sex and $\log _{e}$ BMI as covariates, in a logistic regression analysis.

For quantitative traits in relation to genotypes, a general linear statistical method was used, applying additive, dominant and recessive models while adjusting for the effect of age and sex (BMI, waist and waist to hip ratio), or age, sex and $\log _{e}$ BMI (all other traits). The statistical analyses were performed using the SPSS (SPSS, Chicago, IL, USA) program. A $p$ value $<0.05$ was considered significant.

\section{Results}

The allele and genotype distribution are summarised in Table 2. All three variants genotyped were in Hardy-

Table 2 Association of candidate SNPs in KCNQ1 with type 2 diabetes in participants with type 2 diabetes and in controls

\begin{tabular}{|c|c|c|c|c|c|c|c|c|c|}
\hline \multirow{2}{*}{$\begin{array}{l}\text { SNP } \\
\text { Allele }\end{array}$} & \multirow[t]{2}{*}{ Group } & \multicolumn{3}{|l|}{ Allele data } & \multicolumn{3}{|c|}{ Genotype distribution (\%) } & \multicolumn{2}{|l|}{ Additive model } \\
\hline & & $\begin{array}{l}\text { Frequency }{ }^{a} \\
(\%)\end{array}$ & $\begin{array}{l}\text { OR } \\
(95 \% \mathrm{CI})\end{array}$ & $p$ value & $\mathrm{C} / \mathrm{C}$ & $\mathrm{C} / \mathrm{R}$ & $\mathrm{R} / \mathrm{R}$ & $\begin{array}{l}\text { OR } \\
(95 \% \mathrm{CI})\end{array}$ & $p$ value ${ }^{\mathrm{b}}$ \\
\hline \multirow[t]{2}{*}{$\begin{array}{l}\mathrm{rs} 2237892 \\
\mathrm{~T}^{\mathrm{c}}, \mathrm{C}^{\mathrm{d}}\end{array}$} & Case & 69.6 & \multirow[t]{2}{*}{$\begin{array}{l}1.19 \\
(1.08-1.31)\end{array}$} & \multirow[t]{2}{*}{$3.0 \times 10^{-4}$} & $165(8.8)$ & $813(43.2)$ & 902 (48.0) & \multirow[t]{2}{*}{$\begin{array}{l}1.23 \\
(1.11-1.36)^{\mathrm{e}}\end{array}$} & \multirow[t]{2}{*}{$1.1 \times 10^{-4}$} \\
\hline & Control & 65.8 & & & $224(11.2)$ & $919(46.0)$ & $853(42.7)$ & & \\
\hline \multirow[t]{2}{*}{$\begin{array}{l}\text { rs2237895 } \\
\mathrm{C}^{\mathrm{c}, \mathrm{d}}, \mathrm{A}\end{array}$} & Case & 34.6 & \multirow[t]{2}{*}{$\begin{array}{l}1.20 \\
(1.09-1.32)\end{array}$} & \multirow[t]{2}{*}{$1.9 \times 10^{-4}$} & $209(11.1)$ & $886(47.0)$ & $790(41.9)$ & \multirow[t]{2}{*}{$\begin{array}{l}1.23 \\
(1.11-1.37)^{\mathrm{f}}\end{array}$} & \multirow[t]{2}{*}{$7.8 \times 10^{-5}$} \\
\hline & Control & 30.6 & & & $169(8.5)$ & $883(44.3)$ & $942(47.2)$ & & \\
\hline \multirow[t]{2}{*}{$\begin{array}{l}\text { rs2237897 } \\
\mathrm{T}^{\mathrm{c}}, \mathrm{C}^{\mathrm{d}}\end{array}$} & Case & 68.4 & \multirow[t]{2}{*}{$\begin{array}{l}1.24 \\
(1.13-1.36)\end{array}$} & \multirow[t]{2}{*}{$3.9 \times 10^{-5}$} & $183(9.7)$ & $822(43.8)$ & $873(46.5)$ & \multirow[t]{2}{*}{$\begin{array}{l}1.28 \\
(1.16-1.41)^{\mathrm{g}}\end{array}$} & \multirow[t]{2}{*}{$2.0 \times 10^{-6}$} \\
\hline & Control & 63.6 & & & $271(13.6)$ & $912(45.7)$ & 813 (40.7) & & \\
\hline
\end{tabular}

${ }^{\mathrm{a}}$ Risk allele frequency

${ }^{\mathrm{b}}$ Adjusted for age, sex and $\log _{e} \mathrm{BMI}$

${ }^{\mathrm{c}}$ Minor allele

${ }^{\mathrm{d}}$ Risk allele

$\operatorname{PAR}(\%)={ }^{\mathrm{e}} 23,{ }^{\mathrm{f}} 12.6,{ }^{\mathrm{g}} 27.3$

$\mathrm{C} / \mathrm{C}$, homozygous for minor allele; $\mathrm{C} / \mathrm{R}$, heterozygous for minor allele; $\mathrm{R} / \mathrm{R}$, homozygous for common allele 
Weinberg equilibrium in both the case and control groups. Allele frequency ORs of the three SNPs, rs2237892 (OR $1.19,95 \%$ CI $1.08-1.31, p=3.0 \times 10^{-4}$ ), rs2237895 (OR $1.20,95 \%$ CI $\left.1.09-1.32, p=1.9 \times 10^{-4}\right)$ and $\mathrm{rs} 2237897$ (OR $1.24,95 \%$ CI $1.13-1.36, p=3.9 \times 10^{-5}$ ) were significantly associated with type 2 diabetes in our sample. The risk alleles were in the same direction as in previous studies $[18,19]$. The best-fitting genetic model for all three was the additive model (see Electronic supplementary material [ESM] Table 1). Under the additive model with adjustment for age, sex and $\log _{e}$ BMI, significant association was detected in all three polymorphisms (rs2237892, OR 1.23, $95 \%$ CI $1.11-1.36, p=1.1 \times 10^{-4}, \mathrm{PAR}=23.9 \%$; rs2237895, OR $1.23,95 \%$ CI $1.11-1.37, p=7.8 \times 10^{-5}, \mathrm{PAR}=12.6 \%$; rs2237897, OR 1.28, 95\% CI 1.16-1.41, $p=2.0 \times 10^{-6}$, PAR $=27.3 \%$; Table 2).

The LD structure (rs2237892/rs2237895/rs2237897) is shown in Fig. 1. LD coefficients $\left(D^{\prime}\right.$ and $\left.r^{2}\right)$ among the three variants (see ESM Table 2) suggested that the degree of linkage disequilibrium was relatively high. So haplotypes were constructed with all three variants and the frequencies of haplotypes were then analysed by excluding the rare haplotypes (those below $2 \%$ frequency in cases or controls); this revealed a significant difference in the distribution of the global haplotypes between the type 2 diabetes group and the normal controls $\left(p=2.6 \times 10^{-5}\right)$. The C-C-C haplotype frequency was significantly higher $\left(p=2.1 \times 10^{-3}\right)$ and the T-A-T haplotype frequency was significantly lower $\left(p=4.0 \times 10^{-5}\right)$ in the group with type 2 diabetes compared with the control group (see ESM Table 3).

As treatment for diabetes may have affected metabolic relationships, only non-diabetic individuals were included

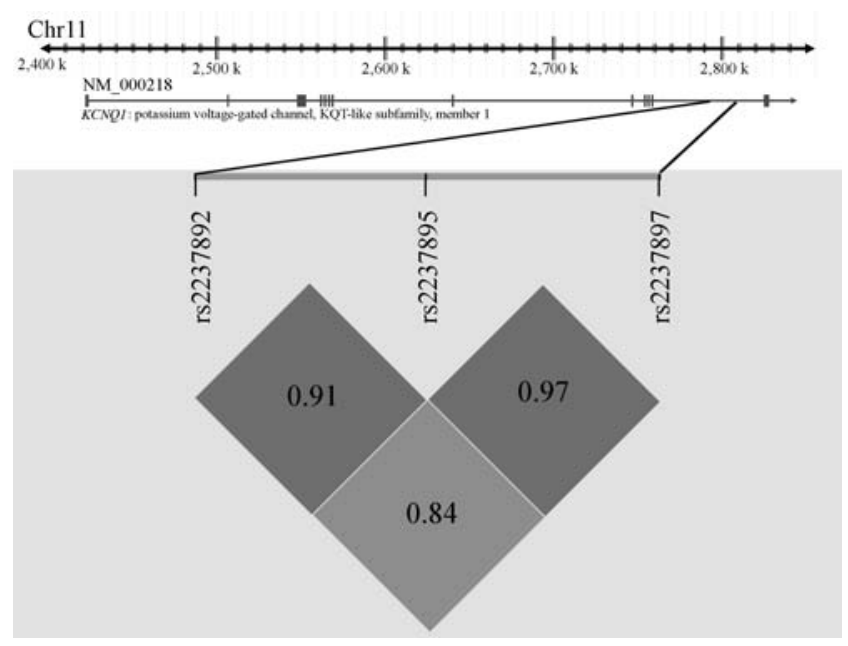

Fig. 1 Linkage disequilibrium structure of the SNPs in KCNQ1. Pairwise $D^{\prime}$ values are colour coded: high $D^{\prime}$ values are dark, low $D^{\prime}$ values are light (values were generated by SHEsis software [22]). The numbers shown at the top represent the degrees of the location of the region on chromosome 11 (Chr11) in the metabolic traits analysis. We found all three variants were associated with BMI and waist measurement, with the homozygous carriers of diabetes-associated allele showing the lowest value. Under the recessive model, rs2237892 and rs2237897 were associated with $\mathrm{HbA}_{1 \mathrm{c}}$ levels and rs2237892 also showed association with fasting plasma glucose levels under the additive model (Table 3). Apart from these associations, the variants were not associated with any other measures in our study.

\section{Discussion}

We found the variants located at intron 15 of KCNQ1, rs2237892, rs2237895 and rs2237897, to be associated with type 2 diabetes. These results are consistent with previous studies [18-20]. The variant rs2237897 showed the strongest association with type 2 diabetes after testing for independent effects, which was consistent with the study of Tan et al. [20]. In addition, the conditional independent effects test of rs2237892, rs2237895 and rs2237897 confirmed that they were in a linkage disequilibrium block, as the effects of rs 2237892 and rs2237895 on type 2 diabetes could be equally attributable to rs2237897 (see ESM Table 4).

$K C N Q 1$, which encompasses $404 \mathrm{~kb}$, is located at chromosome $11 \mathrm{p} 15.5$, not far from a candidate region at $11 \mathrm{p} 13-\mathrm{p} 12$ that two independent studies have linked to type 2 diabetes [24, 25]. KCNQ1 encodes a pore-forming subunit of the voltage-dependent $\mathrm{K}^{+}$ion channel, which is expressed mainly in the heart and, to a lesser extent, in the brain, adipose tissue and pancreas. The two most important roles of potassium voltage-gated channel, KQT-like (KCNQ1) channels are: (1) repolarisation of the cardiac tissue following an action potential; and (2) water and salt transport in epithelial tissues. Moreover, mutations in $K C N Q 1$ can lead to dysfunction of the channel and cause the cardiac long QT syndrome LQTS1 that, in turn, may lead to serious arrhythmias, ventricular fibrillation and cardiac arrest. Kcnq1-knockout mice have been reported to show cardiac dysfunctions such as prolonged QT interval, hypochlorhydria, hypergastrinaemia, gastric hyperplasia and vacuolation of the parietal cells [26, 27]. For type 2 diabetes, homozygous Kcnq1-null mice have been reported not to show hyperglycaemia or glucose intolerance, and the contribution of the $K C N Q 1$-encoded protein to the molecular pathogenesis of type 2 diabetes remains unclear [19]. We found that homozygous carriers of diabetes-associated allele showed the lowest BMI in the control group, which contradicted the theory that weight gain may increase the risk of diabetes. This suggests that the KCNQ1 gene may impact on the pathogenesis of diabetes through pathways other than weight gain. The association of $\mathrm{HbA}_{1 \mathrm{c}}$ levels and 
Table 3 Effect of candidate SNP variant genotypes on clinical and biochemical variables in control individuals

\begin{tabular}{|c|c|c|c|c|c|c|c|c|c|}
\hline \multirow[t]{2}{*}{ SNP } & \multirow{2}{*}{$\begin{array}{l}\text { Risk } \\
\text { allele }\end{array}$} & \multirow{2}{*}{$\begin{array}{l}\text { Non-risk } \\
\text { allele }\end{array}$} & \multirow{2}{*}{$\begin{array}{l}\text { Phenotypic } \\
\text { characteristic }^{\mathrm{a}}\end{array}$} & \multicolumn{3}{|l|}{ Genotypes } & \multicolumn{3}{|l|}{$p$ value $^{\mathrm{b}}$} \\
\hline & & & & $\mathrm{C} / \mathrm{C}$ & $\mathrm{C} / \mathrm{R}$ & $\mathrm{R} / \mathrm{R}$ & Additive & Dominant & Recessive \\
\hline \multirow[t]{7}{*}{ rs2237892 } & \multirow[t]{7}{*}{$\mathrm{C}$} & \multirow[t]{7}{*}{$\mathrm{T}$} & BMI $\left(\mathrm{kg} / \mathrm{m}^{2}\right)$ & $24.3 \pm 3.13$ & $24.7 \pm 3.30$ & $24.7 \pm 3.42$ & 0.039 & 0.483 & 0.020 \\
\hline & & & Waist (cm) & $82.9 \pm 9.08$ & $83.2 \pm 8.79$ & $84.9 \pm 16.3$ & 0.043 & 0.019 & 0.223 \\
\hline & & & Waist to hip ratio & $0.86 \pm 0.06$ & $0.86 \pm 0.07$ & $0.86 \pm 0.07$ & 0.635 & 0.492 & 0.844 \\
\hline & & & $\begin{array}{l}\text { Fasting plasma glucose } \\
(\mathrm{mmol} / \mathrm{l})\end{array}$ & $4.85 \pm 0.66$ & $4.83 \pm 0.60$ & $4.75 \pm 0.71$ & 0.051 & 0.047 & 0.190 \\
\hline & & & $\mathrm{HbA}_{1 \mathrm{c}}(\%)$ & $5.81 \pm 0.55$ & $5.75 \pm 0.53$ & $5.77 \pm 0.69$ & 0.064 & 0.781 & 0.012 \\
\hline & & & $\begin{array}{l}\text { Total cholesterol } \\
(\mathrm{mmol} / \mathrm{l})\end{array}$ & $4.52 \pm 0.90$ & $4.48 \pm 0.88$ & $4.53 \pm 0.80$ & 0.517 & 0.583 & 0.221 \\
\hline & & & $\begin{array}{l}\text { Triacylglycerol } \\
(\mathrm{mmol} / \mathrm{l})\end{array}$ & $1.64 \pm 1.08$ & $1.58 \pm 1.10$ & $1.60 \pm 0.85$ & 0.404 & 0.978 & 0.255 \\
\hline \multirow[t]{7}{*}{ rs2237895 } & \multirow[t]{7}{*}{$\mathrm{C}$} & \multirow[t]{7}{*}{ A } & BMI $\left(\mathrm{kg} / \mathrm{m}^{2}\right)$ & $23.9 \pm 2.86$ & $24.5 \pm 3.34$ & $24.6 \pm 3.22$ & 0.027 & 0.200 & 0.006 \\
\hline & & & Waist (cm) & $82.0 \pm 8.47$ & $83.0 \pm 9.06$ & $83.8 \pm 11.1$ & 0.012 & 0.036 & 0.048 \\
\hline & & & Waist to hip ratio & $0.86 \pm 0.05$ & $0.86 \pm 0.06$ & $0.86 \pm 0.06$ & 0.093 & 0.058 & 0.655 \\
\hline & & & $\begin{array}{l}\text { Fasting plasma glucose } \\
(\mathrm{mmol} / \mathrm{l})\end{array}$ & $4.82 \pm 0.69$ & $4.85 \pm 0.62$ & $4.81 \pm 0.65$ & 0.188 & 0.081 & 0.913 \\
\hline & & & $\mathrm{HbA}_{1 \mathrm{c}}(\%)$ & $5.75 \pm 0.57$ & $5.78 \pm 0.55$ & $5.79 \pm 0.57$ & 0.651 & 0.779 & 0.595 \\
\hline & & & Total cholesterol (mmol/l) & $4.42 \pm 0.84$ & $4.51 \pm 0.88$ & $4.51 \pm 0.88$ & 0.748 & 0.811 & 0.245 \\
\hline & & & $\begin{array}{l}\text { Triacylglycerol } \\
(\mathrm{mmol} / \mathrm{l})\end{array}$ & $1.59 \pm 1.10$ & $1.61 \pm 1.03$ & $1.61 \pm 1.09$ & 0.986 & 0.831 & 0.733 \\
\hline \multirow[t]{7}{*}{ rs2237897 } & \multirow[t]{7}{*}{$\mathrm{C}$} & \multirow[t]{7}{*}{$\mathrm{T}$} & BMI $\left(\mathrm{kg} / \mathrm{m}^{2}\right)$ & $24.2 \pm 3.15$ & $24.7 \pm 3.28$ & $24.9 \pm 3.36$ & 0.002 & 0.074 & 0.002 \\
\hline & & & Waist (cm) & $82.7 \pm 9.13$ & $83.5 \pm 8.80$ & $84.6 \pm 15.2$ & 0.004 & 0.017 & 0.018 \\
\hline & & & Waist to hip ratio & $0.86 \pm 0.06$ & $0.86 \pm 0.06$ & $0.86 \pm 0.06$ & 0.576 & 0.703 & 0.608 \\
\hline & & & $\begin{array}{l}\text { Fasting plasma glucose } \\
(\mathrm{mmol} / \mathrm{l})\end{array}$ & $4.82 \pm 0.66$ & $4.85 \pm 0.61$ & $4.77 \pm 0.68$ & 0.562 & 0.155 & 0.854 \\
\hline & & & $\mathrm{HbA}_{1 \mathrm{c}}(\%)$ & $5.80 \pm 0.55$ & $5.76 \pm 0.53$ & $5.77 \pm 0.66$ & 0.133 & 0.662 & 0.047 \\
\hline & & & Total cholesterol (mmol/l) & $4.52 \pm 0.90$ & $4.47 \pm 0.87$ & $4.56 \pm 0.83$ & 0.630 & 0.368 & 0.193 \\
\hline & & & $\begin{array}{l}\text { Triacylglycerol } \\
(\mathrm{mmol} / \mathrm{l})\end{array}$ & $1.63 \pm 1.11$ & $1.58 \pm 1.03$ & $1.67 \pm 1.18$ & 0.991 & 0.332 & 0.508 \\
\hline
\end{tabular}

Data are means \pm SD

${ }^{a}$ Multiple linear regression was carried out after logarithmic transformation for data not in normal distribution

${ }^{\mathrm{b}}$ Adjusted for age and sex (BMI, waist and waist to hip ratio), or age, sex and $\log _{e}$ BMI (all other traits)

$\mathrm{C} / \mathrm{C}$, homozygous for risk allele; $\mathrm{C} / \mathrm{R}$, heterozygous for risk allele; $\mathrm{R} / \mathrm{R}$, homozygous for non-risk allele

fasting plasma glucose levels in our study, and the association of higher fasting glucose levels and reduced corrected insulin response at $120 \mathrm{~min}$ in the study of Tan et al. [20], in conjunction with the lower homeostasis model assessment for beta cell function or corrected insulin response apparent for C-C homozygotes of rs2237892 in the study of Yasuda et al. [18], may reflect a functional role for this channel in beta cell function and the pathogenesis of type 2 diabetes. Thus, further studies will be useful to replicate these promising findings and to fully delineate the role of $K C N Q 1$.

In the present study, the distribution of haplotypes constructed by rs2237892, rs2237895 and rs2237897 showed significant differences between cases and controls, particularly the C-C-C haplotype and the T-A-T haplotype. Thus, it can be seen that the three variants are in an $\mathrm{LD}$ block. However, no variant in this region has been detected to have a direct function, so we suggest that there may be one or more other functional variants in this region of $K C N Q 1$. In a recent study, large gene deletions and duplications in $K C N Q 1$ were identified in people with long QT syndrome [28]. This suggests that copy-number variants in $K C N Q 1$ also play a role in associated complex diseases. To clarify the role of $K C N Q 1$ in susceptibility to type 2 diabetes, further research is needed into the SNPs and copynumber variants.

In addition, compared with the controls in previous studies (see ESM Table 5), the minor allele frequencies of all three variants in our population from mainland China were higher or lower than in other populations; for example, the frequency of SNP rs2237897 in our Chinese sample was close to that in the Singapore Chinese 
population, higher than that in the Japanese population and completely different from the frequency in the Danish population ( $63.8 \%, 65 \%, 61 \%$ and $96 \%$, respectively) [1820]. These results confirmed the differences in frequencies of some genetic variations among different ethnic groups and different geographic regions. At the same time, these differences also highlight the need to extend genome-wide association scans and subsequent replication studies to different populations.

In summary, we detected the association of $K C N Q 1$ with type 2 diabetes and some diabetes-related traits in the population of mainland China. In addition, the haplotype distribution was found to be significantly different between cases and controls. These findings may be useful in further research into the pathogenesis of type 2 diabetes, as well as in advancing clinical practice and public health genomics.

Acknowledgements We thank the individuals who participated in the present study. This work was supported by grants from the National Key Technology R\&D Program (2006BAI05A05), S973 Program (2007CB947300), 863 Program (2006AA02A407), S973 Program (2006CB910601), the Opening Project of Shanghai Key Laboratory of Complex Prescription (07DZ22917), the ShanghaiUnilever Research and Development Fund (06SU07007), the Shanghai Leading Academic Discipline Project (B205), the Chinese Nutrition Society (05015), the Shanghai Municipality Science \& Technology Commission (05JC14090) and the Chinese Academy of Sciences (KSCX2-YW-R-01).

Duality of interest statement The authors declare that there is no duality of interest associated with this manuscript.

Open Access This article is distributed under the terms of the Creative Commons Attribution Noncommercial License which permits any noncommercial use, distribution, and reproduction in any medium, provided the original author(s) and source are credited.

\section{References}

1. Wild S, Roglic G, Green A, Sicree R, King H (2004) Global prevalence of diabetes: estimates for the year 2000 and projections for 2030. Diabetes Care 27:1047-1053

2. Grant SF, Thorleifsson G, Reynisdottir I et al (2006) Variant of transcription factor 7-like 2 (TCF7L2) gene confers risk of type 2 diabetes. Nat Genet 38:320-323

3. Gloyn AL, Weedon MN, Owen KR et al (2003) Large-scale association studies of variants in genes encoding the pancreatic beta-cell KATP channel subunits Kir6.2 (KCNJ11) and SUR1 (ABCC8) confirm that the KCNJ11 E23K variant is associated with type 2 diabetes. Diabetes 52:568-572

4. Altshuler D, Hirschhorn JN, Klannemark M et al (2000) The common PPARgamma Pro12Ala polymorphism is associated with decreased risk of type 2 diabetes. Nat Genet 26:76-80
5. Zeggini E, Weedon MN, Lindgren CM et al (2007) Replication of genome-wide association signals in UK samples reveals risk loci for type 2 diabetes. Science 316:1336-1341

6. WTCCC (2007) Genome-wide association study of 14,000 cases of seven common diseases and 3,000 shared controls. Nature 447:661-678

7. Steinthorsdottir V, Thorleifsson G, Reynisdottir I et al (2007) A variant in CDKAL1 influences insulin response and risk of type 2 diabetes. Nat Genet 39:770-775

8. Sladek R, Rocheleau G, Rung J et al (2007) A genome-wide association study identifies novel risk loci for type 2 diabetes. Nature 445:881-885

9. Scott LJ, Mohlke KL, Bonnycastle LL et al (2007) A genomewide association study of type 2 diabetes in Finns detects multiple susceptibility variants. Science 316:1341-1345

10. Saxena R, Voight BF, Lyssenko V et al (2007) Genome-wide association analysis identifies loci for type 2 diabetes and triglyceride levels. Science 316:1331-1336

11. Wu Y, Li H, Loos RJ et al (2008) Common variants in CDKAL1, CDKN2A/B, IGF2BP2, SLC30A8, and HHEX/IDE genes are associated with type 2 diabetes and impaired fasting glucose in a Chinese Han population. Diabetes 57:2834-2842

12. Ng MC, Park KS, Oh B et al (2008) Implication of genetic variants near TCF7L2, SLC30A8, HHEX, CDKAL1, CDKN2A/B, IGF2BP2, and FTO in type 2 diabetes and obesity in 6, 719 Asians. Diabetes 57:2226-2233

13. Lee YH, Kang ES, Kim SH et al (2008) Association between polymorphisms in SLC30A8, HHEX, CDKN2A/B, IGF2BP2, FTO, WFS1, CDKAL1, KCNQ1 and type 2 diabetes in the Korean population. J Hum Genet 53:11-12

14. Rong R, Hanson RL, Ortiz D et al (2008) Association analysis of variation in/near FTO, CDKAL1, SLC30A8, HHEX, EXT2, IGF2BP2, LOC387761 and CDKN2B with type 2 diabetes and related quantitative traits in Pima Indians. Diabetes 58:478-488

15. Hertel JK, Johansson S, Raeder H et al (2008) Genetic analysis of recently identified type 2 diabetes loci in 1,638 unselected patients with type 2 diabetes and 1,858 control participants from a Norwegian population-based cohort (the HUNT study). Diabetologia 51:971-977

16. Liu Y, Yu L, Zhang D et al (2008) Positive association between variations in CDKAL1 and type 2 diabetes in Han Chinese individuals. Diabetologia 51:2134-2137

17. Cauchi S, Meyre D, Durand E et al (2008) Post genome-wide association studies of novel genes associated with type 2 diabetes show gene-gene interaction and high predictive value. PLoS ONE 3:e2031

18. Yasuda K, Miyake K, Horikawa Y et al (2008) Variants in KCNQ1 are associated with susceptibility to type 2 diabetes mellitus. Nat Genet 40:1092-1097

19. Unoki H, Takahashi A, Kawaguchi $T$ et al (2008) SNPs in KCNQ1 are associated with susceptibility to type 2 diabetes in East Asian and European populations. Nat Genet 40:1098-1102

20. Tan JT, Nurbaya S, Gardner D, Sandra Y, Tai ES, Ng DP (2009) Genetic variation in KCNQ1 associates with fasting glucose and beta-cell function: a study of 3734 subjects comprising three ethnicities living in Singapore. Diabetes. doi:10.2337/db08-1138

21. Huang K, Tang W, Tang R et al (2008) Positive association between OLIG2 and schizophrenia in the Chinese Han population. Hum Genet 122:659-660

22. Shi YY, He L (2005) SHEsis, a powerful software platform for analyses of linkage disequilibrium, haplotype construction, and genetic association at polymorphism loci. Cell Res 15: 97-98 
23. Bruzzi P, Green SB, Byar DP, Brinton LA, Schairer C (1985) Estimating the population attributable risk for multiple risk factors using case-control data. Am J Epidemiol 122:904-914

24. Nawata H, Shirasawa S, Nakashima N et al (2004) Genome-wide linkage analysis of type 2 diabetes mellitus reconfirms the susceptibility locus on $11 \mathrm{p} 13-\mathrm{p} 12$ in Japanese. J Hum Genet 49:629-634

25. Mori Y, Otabe S, Dina C et al (2002) Genome-wide search for type 2 diabetes in Japanese affected sib-pairs confirms susceptibility genes on $3 \mathrm{q}, 15 \mathrm{q}$, and $20 \mathrm{q}$ and identifies two new candidate loci on $7 \mathrm{p}$ and $11 \mathrm{p}$. Diabetes 51:1247-1255
26. Lee MP, Ravenel JD, Hu RJ et al (2000) Targeted disruption of the Kvlqt1 gene causes deafness and gastric hyperplasia in mice. J Clin Invest 106:1447-1455

27. Casimiro MC, Knollmann BC, Ebert SN et al (2001) Targeted disruption of the Kcnq1 gene produces a mouse model of Jervell and Lange-Nielsen Syndrome. Proc Natl Acad Sci USA 98:25262531

28. Eddy CA, MacCormick JM, Chung SK et al (2008) Identification of large gene deletions and duplications in KCNQ1 and $\mathrm{KCNH} 2$ in patients with long QT syndrome. Heart Rhythm $5: 1275-1281$ 